\title{
PROFESSIONAL IDIOMS IN A PRACTICAL COURSE OF RUSSIAN LANGUAGE FOR FOREIGNERS (BASED ON THE LANGUAGE OF MEDICINE)
}

\author{
Olga P. Ignatenko \\ Volgograd State Medical University, Volgograd, Russian Federation \\ Yuliya G. Fateeva \\ Volgograd State Medical University, Volgograd, Russian Federation
}

\begin{abstract}
The article is devoted to the problem of forming professional communicative competence of foreign students. The main attention is paid to professional phraseological terms, because they (due to their idiomatic nature) often have national and cultural specifics, causing considerable difficulties in studying. Material for analysis was the author's card file of medical phraseological units (more than 100 units), compiled on the basis of dictionaries of medical terms and works on the vocabulary of the medical field.

Based on the traditional definition of phraseological units as stable formations, the importance of which is not motivated by the values of the components included in them, the authors offered several classifications of medical phraseological units. In teaching phraseological units it is advisable to use classifications based on structural or semantic principles. It is shown that the division of phraseological units that is traditional for linguistics in terms of the degree of adhesion of words in their composition cannot be used in a foreign language audience, since students have difficulties in understanding this criterion.

The article substantiates the necessity of studying medical phraseology already at the initial stage of mastering the language of the profession. The system of tasks (for the initial and advanced stages of learning of Russian language) is proposed, the sequence of which is determined by the structure and semantics of phraseological units. Recommendations for working with professional phraseology can be applied when studying by foreign students of Russian professional idioms not only in medical schools, but also in other universities that provide training for students in other areas.

Key words: idiom, medical idioms, Russian as a foreign language, professional vocabulary, communicative competence, scientific style of speech.

Citation. Ignatenko O.P., Fateeva Yu.G. Professional Idioms in a Practical Course of Russian Language for Foreigners (based on the Language of Medicine). Vestnik Volgogradskogo gosudarstvennogo universiteta. Serija 2, Jazykoznanije [Science Journal of Volgograd State University. Linguistics], 2017, vol. 16, no. 2, pp. 181-188. (in Russian). DOI: https://doi.org/10.15688/jvolsu2.2017.2.20.
\end{abstract}

УДК 811.161.1’367

Дата поступления статьи: 23.12.2016

ББК $81.411 .2-36$

Дата принятия статьи: 28.04.2017

\section{ПРОФЕССИОНАЛЬНЫЕ ФРАЗЕОЛОГИЗМЫ \\ В ПРАКТИЧЕСКОМ КУРСЕ РУССКОГО ЯЗЫКА КАК ИНОСТРАННОГО (НА МАТЕРИАЛЕ ЯЗЫКА МЕДИЦИНЫ) \\ Ольга Петровна Игнатенко}

Волгоградский государственный медицинский университет, г. Волгоград, Российская Федерация

\section{Юлия Геннадиевна Фатеева}

Волгоградский государственный медицинский университет, г. Волгоград, Российская Федерация

Аннотация. Статья посвящена проблеме формирования профессиональной коммуникативной компетенции у студентов-иностранцев. Основное внимание уделено закрепленным в качестве терминов профес- 
сиональным фразеологизмам, поскольку они в силу своей идиоматичности, насыщенности внеязыковой информацией, часто имеющей национально-культурную специфику, вызывают значительные трудности в освоении. Материалом для анализа послужила авторская картотека медицинских фразеологизмов (более 100 единиц), составленная на основе словарей медицинских терминов и работ, посвященных лексике медицинской сферы.

С опорой на традиционное определение, отражающее представление о фразеологизмах как устойчивых образованиях, значение которых не мотивировано значениями входящих в них компонентов, авторами предложено несколько классификаций медицинских фразеологизмов. Установлено, что при обучении целесообразно использовать классификации, в основе которых лежат структурный или семантический принципы; показано, что традиционное для лингвистики деление фразеологизмов по степени спаянности слов в их составе не может быть применено в иноязычной аудитории, поскольку у студентов возникают трудности в понимании этого критерия.

В статье обоснована необходимость изучения медицинской фразеологии уже на начальном этапе овладения языком профессии; предложена система заданий (для начального и продвинутого этапов освоения русского языка), последовательность которых обусловлена как структурой, так и семантикой фразеологических единиц. Рекомендации по работе с профессиональными фразеологизмами могут быть применены при изучении иностранными студентами русской профессиональной идиоматики не только в медицинском, но и в других вузах.

Ключевые слова: фразеологизм, медицинский фразеологизм, русский язык как иностранный, профессиональная лексика, коммуникативная компетенция, научный стиль речи.

Цитирование. Игнатенко О. П., Фатеева Ю. Г. Профессиональные фразеологизмы в практическом курсе русского языка как иностранного (на материале языка медицины) // Вестник Волгоградского государственного университета. Серия 2, Языкознание. -2017. - Т. 16, № 2. - С. 181-188. -DOI: https://doi.org/10.15688/jvolsu2.2017.2.20.

\section{1. Введение}

Целью изучения русского языка как иностранного в российском вузе является приобретение профессиональной коммуникативной компетенции. Следовательно, основной акцент на занятиях РКИ делается на знакомстве со спецификой профессиональной речи, проводится ее лингвистический и культурологический анализ, формируются навыки оптимального использования всех средств языка. Для этого особое внимание уделяется изучению научного стиля речи, лежащего в основе профессионального общения.

Значительные трудности в овладении языком профессии у студентов-иностранцев вызывают фразеологизмы в силу их идиоматичности, насыщенности внеязыковой информацией, часто имеющей национально-культурную специфику. Несмотря на то что изучению русской фразеологии в иноязычной аудитории уделяется значительное внимание как в научно-теоретическом, так и в практико-методическом аспектах, в современной практике преподавания русского языка как иностранного проблема овладения русской фразеологией остается достаточно сложной в методическом отношении. Это утверждение справедли- во и по отношению к профессиональной медицинской фразеологии.

Ее изучение в отечественной лингвистике - направление новое: этот объект профессиональной медицинской лексики в разных аспектах представлен в работах Н.В. Ефремовой [2012], Ю.А. Сотникова [2013], Н.В. Гончаренко [2014], Е.А. Момот, А.А. Мартиросян, А.К. Газарянц [2016] и др. Некоторые аспекты данной темы рассмотрены в трудах о медицинских метафорах, например, в публикациях О.С. Зубковой [2008; 2011]. Однако возможности использования достижений изучения медицинской фразеологии остаются не в полной мере реализованными в практике преподавания русского языка студентам-иностранцам.

В данной статье предложены методические приемы обучения профессиональной фразеологии на материале языка медицины, богатого фразеологическими оборотами, многие из которых закрепляются в статусе терминов.

\section{2. Классификации медицинских фразеологизмов}

Принимая во внимание ведущиеся до сих пор дискуссии о содержании термина «фразе- 
ологизм», мы придерживаемся широкого его понимания, отраженного в «Лингвистическом энциклопедическом словаре»: фразеологизм (фразеологическая единица) определяется как «общее название семантически связанных сочетаний слов и предложений, которые, в отличие от сходных с ними по форме синтаксических структур, не производятся в соответствии с общими закономерностями выбора и комбинации слов при организации высказывания, а воспроизводятся в речи в фиксированном соотношении семантической структуры и определенного лексико-грамматического состава» [Телия, 1990, с. 559]. Эта дефиниция отражает утвердившееся в науке представление о фразеологизмах как устойчивых образованиях, не мотивированных значением входящих в них компонентов, и позволяет включать в их состав профессиональные устойчивые словосочетания.

Медицинские фразеологизмы разнообразны по семантике и структуре, что создает дополнительные сложности при их изучении в иностранной аудитории. Среди методических изданий есть пособия и по изучению медицинской фразеологии, однако в них классификации этих лексических единиц либо отсутствуют, либо представлены противоречиво. Так, Ю.А. Сотников в своем методическом пособии привел около ста медицинских фразеологизмов, которые «можно использовать для повышения уровня знаний студентов и развития интереса к изучению медицины» [Сотников, 2013, с. 4], но не классифицировал их. Е.А. Момот, А.А. Мартиросян, А.К. Газарянц выделили несколько групп медицинских фразеологизмов: связанные с животным миром, с мифологией, с разделами медицины, с профессиями и спортом, образованные с помощью фамилий ученых, имеющие бытовой характер [Момот, Мартиросян, Газарянц, 2016, с. 6-7], однако, как отметили сами авторы, фразеологизмы были изучены не столь глубоко [Момот, Мартиросян, Газарянц, 2016, с. 6], а разработанная классификация противоречива, так как дана на разных основаниях.

Нами предлагается несколько классификаций медицинских фразеологизмов, в основе которых лежат грамматический признак (по главному слову), семантический признак или принцип «схожести» названных объектов или явлений (значение медицинского фразеологизма обусловлено значением составляющих его слов) и др. При этом общепринятое деление фразеологизмов по типу связи (спаянности) слов в составе фразеологической единицы не берется во внимание, поскольку в иноязычной аудитории существуют определенные трудности понимания степени сращения слов в изучаемых языковых единицах. Картотека, составленная авторами статьи на материале словарей медицинских терминов (см. раздел «Словари») и работ, посвященных лексике медицинской сферы, насчитывает более 100 единиц.

В основу одной из классификаций нами положен принцип «реальности - нереальности» объектов, наименование которых входит в состав фразеологизма: в состав фразеологизмов первой группы входят лексемы, обозначающие реальные объекты или явления (имена ученых, профессии, животные и т. д.), вторая группа представлена фразеологизмами, в состав которых входят имена вымышленных (мифологических, литературных) персонажей и названий нереальных объектов. Каждая из этих групп состоит из нескольких подгрупп.

К первой группе относятся:

- фразеологизмы с названиями животных и птиц (осанка обезьяны, петушиная поход$к а$, симптом «кочачьего мурлыканья», верблюжья походка, заячья губа, волчья пасть, куриная грудь, леопардовая кожа, кошачьи уши, медвежья болезнь и др.);

- фразеологизмы, включающие имена известных врачей: лицо Гиппократа, маска Паркинсона, воротник Стокса, лицо Корвизара, синдром Уэста, синдром Экбома;

- фразеологизмы, образованные по сходству с человеком определенной профессии или рода деятельности: лицо клоуна, лицо свистуна, поза фехтовальщика, грудь сапожника, рука акушера, поза балерины и др.;

- фразеологизмы, образованные на основе сходства с предметом:

- по форме: барабанные палочки, симптом часовых стекол, зубчатое колесо, бамбуковая палка, плавающая льдинка, песочные часы, сосудистые звездочки, клеверовидный череп; 


\section{МАТЕРИАЛЫ И СООБЩЕНИЯ}

- по цвету: медная проволока, алебастровая бледность, бронзовая болезнь, лицо восковой куклы;

- по запаху: болезнь кленового сиропа;

- по звуку: ритм галопа, шум треснувшего горика.

- фразеологизмы, основанные на названии органов или заболеваний (печеночные ладони, легочное сердие, обезглавленная гипертензия, суставные мыши, сердечный горб, струны аппендицита, талия сердияа и др.).

Вторая группа включает:

- мифологические фразеологизмы (голова Медузы, лицо сфинкса, голова Олоферна и др.);

- фразеологизмы, включающие имена литературных героев (синдром Ромео и Джульетты, синдром Алисы в Стране чудес, синдром Мюнхгаузена, синдром Отелло, синдром Квазимодо).

По структуре фразеологизмы делятся на следующие группы:

- «прилагательное + существительное» (считаем целесообразным включить в эту группу и фразеологизм с притяжательными прилагательными, так как грамматическая характеристика данных единиц полностью совпадает с качественными и относительными прилагательными):

- «качественное прилагательное + существительное»: беспокойные ноги, душевная слепота и т. д.;

- «относительное прилагательное + существительное»: песочные часы, бронзовая болезнь, туреиякое седло и т. д.;

- «притяжательное прилагательное + существительное»: заячья губа, волчья пасть, верблюжья походка, бычьи глаза, обезьянья лапа, медвежья болезнь, кошачьи уши, лягушачий живот и др.;

- «существительное + существительное в родительном падеже»: грудь сапожника, рука акушера, поза балерины, крылья ангелочка, шапка Наполеона, клюв попугая и т. д.;

- «причастие + существительное»: замороженное плечо, летающие мушки, обезглавленная гипертензия, плавающая льдинка, свисающая голова.

По семантике (предмету обозначения, называния) фразеологизмы подразделяются на:
- фразеологизмы, называющие симптом: летающие мушки, барабанные палочки, кошачье мурльканье, замороженное плечо, звук треснувшего горшка, симптом рубашки Воскресенского и др.;

- фразеологизмы, называющие заболевание: болезнь кленового сиропа, бронзовая болезнь, болезнь отсутствия пульса, болезнь кошачьей царапины, болезнь легких иепей, солдатская болезнь;

- фразеологизмы, называющие синдромы (в основном, в психиатрии): синдром Ромео и Джульетты, синдром Алисы в Стране чудес, синдром Мюнхгаузена, синдром Отелло, синдром Диогена, синдром Квазимодо и т. п.;

- фразеологизмы, называющие дефекты или изменения (аномалии развития): волчья пасть, заячья губа, грудь сапожника, рука пророка, кошачьи уши, лищо клоуна, шея лягушки;

- фразеологизмы, называющие анатомическое место, часть органа или орган: туреикое седло, талия сердия, висячее сердие, конский хвост и др.;

- фразеологизмы, называющие физиологические процессы: гусиная кожа.

Представленные классификации демонстрируют структурную и семантическую сложность медицинских фразеологизмов, а также разнообразие сфер их использования в профессиональной медицинской коммуникации, которое обусловливает необходимость изучения этих лексических единиц на занятиях со студентами-иностранцами, обучающимися в медицинских вузах России.

\section{3. Приемы изучения медицинской фразеологии в иностранной аудитории}

Изучение лексики иностранного языка, как полагают методисты, наиболее сложная часть освоения иностранного языка: «трудности в преподавании лексики возникают в связи со сложностью лексической семантики, достаточно скрытым характером системности составляющих ее единиц, многоаспектностью слова, обладающего, помимо собственно лексического статуса, еще и грамматическим, словообразовательным, фразеологичес- 
ким, лингвострановедческим и т. д. статусами» [Аркадьева, 2005, с. 202].

В методике обучения иностранному языку принято считать, что основной принцип отбора лексики для начального этапа - это «критерии общеупотребительности лексической единицы, ее семантическая, сочетаемостная и словообразовательная ценность, а также ситуативно-тематическая соотнесенность» [Аркадьева, 2005, с. 205]. В этом случае введение профессиональной фразеологии многим методистам представляется преждевременным. Однако, как показывает практика, изучать элементы профессионального языка необходимо на самых ранних этапах его освоения, поскольку, во-первых, студенты-иностранцы обучаются в стране другого языка, долгое время находятся на ее территории, общаются с носителями языка не только в быту, но и во время клинических практик, начиная с 1 курса, решают возникающие проблемы (в том числе и проблемы с собственным здоровьем); во-вторых, изучение профессиональной лексики, в том числе и фразеологизмов, позволяет расширить тематику имитационных (инсценировочных) упражнений на занятиях, ускорить преодоление страха и языкового барьера.

Полагаем, что последовательность изучения медицинских фразеологизмов целесообразно соотнести как с их структурой, так и с их семантикой.

На начальном этапе освоения русского языка при работе над темой «Имя прилагательное» можно изучать фразеологизмы, образованные по моделям «качественное прилагательное + существительное» и «относительное прилагательное + существительное», поскольку сочетания типа беспокойные ноги, стеклянный человек, песочные часы, сердечный горб, называющие симптомы болезней, отражают одну из особенностей прилагательного в русском языке: они имеют грамматическую сочетаемость с существительным (полную зависимость от его формы).

Одной из грамматических тем, предлагаемых для изучения на 1 курсе, является тема «Характеристика предмета по форме, цвету, вкусу и запаху». В качестве материала в нее могут быть включены фразеологизмы, построенные по моделям «относитель- ное прилагательное + существительное» и «существительное + существительное в родительном падеже», основанные на сходстве по форме (барабанные палочки, осанка обезьяны), по цвету (алебастровая бледность), по запаху (болезнь кленового сиро$n a)$. Учащимся могут быть предложены следующие упражнения:

1. Прочитайте прилагательные и выберите из списка предложенных слов те, от которых данные прилагательные образованы. Определите их значение по словарю.

2. Обратите внимание на лексико-грамматическую сочетаемость данных единиц. У больного отмечается алебастровая бледность, наблюдаются сосудистые звездочки. Ногтевые пластины имеют форму часовых стекол. Фаланги пальцеев имеют форму барабанных палочек. От формы фразеологических единиц можно перейти к их значениям. Учащимся самостоятельно предлагается поработать с медицинскими словарями и найти описание симптомов и болезней, изученных на занятии.

На начальном этапе обучения целесообразно семантизировать перечисленные фразеологизмы с помощью синонимического словосочетания или сравнительного оборота. Например: мертвый палеи - временно бледный палец, утиная походка - идти как утка, петушиная походка - ходить на носках, не ставить ногу на пятку. Эта работа снимет часть трудностей, которые возникнут в дальнейшем при восприятии на слух лекций по специальности на русском языке.

Как на начальном, так и на продвинутом этапах продуктивным является изучение фразеологизмов, построенных по модели «притяжательное прилагательное + существительное». Например, полученное в начале изучения русского языка знание наименований животных (волк, верблюд, бык, обезьяна, кот, лягушка и др.) облегчит понимание значения симптома или патологии: заячья губа, волчья пасть, верблюжья походка, бычьи глаза, обезьянья лапа, кошачьи уши, лягушачий живот. На данном этапе уместно широко использовать наглядные пособия и иллюстрации животных и вводимых симптомов: это облегчит понимание и снимет трудности перевода. Работа с фразеологизмами может 


\section{МАТЕРИАЛЫ И СООБЩЕНИЯ}

проходить в игровой форме. Так, в процессе игры «Кто больше?» студентам предлагается назвать как можно больше симптомов, включающих прилагательные, образованные от наименований животных. Возможно использование игры «Угадай!»: преподаватель демонстрирует наглядный материал по одному из симптомов болезни, а учащиеся должны назвать этот симптом. Эффективным представляется и следующее задание: найдите в «Облаке слов» названия симптомов болезни. Скажите, наименования каких животных в них «спрятаны»:

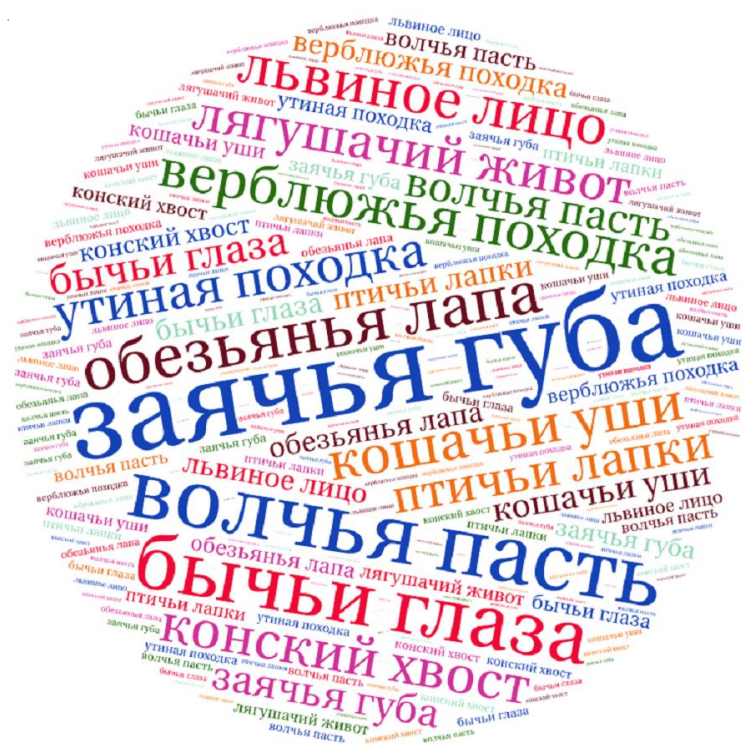

Обратим внимание на то, что подобные фразеологизмы на начальном этапе освоения русского языка необходимо вводить, не делая акцент на особенностях словообразования входящих в их состав слов.

На продвинутом этапе изучения русского языка к семантическому анализу присоединяется анализ модели образования притяжательных прилагательных на примерах фразеологизмов типа: конский хвост, львиное лицо, птичье лищо, птичьи лапки и др. В качестве задания для работы с подобными лексическими единицами может быть предложено следующее: заполните пропуски подходящими по смыслу притяжательными прилагательными в нужной форме. Учащимся предлагается набор симптомов типа: ... nacmb, ... губа, ... уии, ... походка, лапа и т. п. В словах для справок предлагаются на выбор: заячий, волчий, верблюжсий, кочачий, обезьяний и т. п.
При изучении на продвинутом этапе грамматической темы «Причастие» целесообразно в качестве наглядного примера привести фразеологизмы, созданные по модели «причастие + существительное»: плавающая льдинка, летаюшие мушки, свисающая голова. Этот лексический материал можно использовать и на так называемом грамматическом уровне (образование причастий), и на лексическом. В результате такой работы происходит расширение словарного запаса профессиональной речи учащихся. На грамматическом уровне учащимся может быть предложено задание трансформировать предложения во фразеологизмы модели «причастие + существительное»: Льдинка, которая плавает. - Плавающзая льдинка.

На лексическом уровне учащимся предлагается подобрать правильное толкование фразеологизмов из предложенных преподавателем. Например: летающие мушки - это: 1) появление движущихся черных пятен перед глазами; 2) появление зрительных галлюцинаций в виде маленьких насекомых (мух).

На продвинутом этапе изучения научного стиля речи медицины продолжается работа с фразеологизмами и устойчивыми словосочетаниями в научном контексте, то есть при работе с текстами по терапии, хирургии, офтальмологии, урологии, неврологии, инфекционным болезням и т. д. Фразеологизмы включены в описание клинической картины заболевания: белая опухоль (при артрите), заячий глаз (при неврите лицевого нерва), лицо миопата (при миопатии), либо заключены в самом названии болезнь кошачьей царапины. Данные единицы целесообразно включить в предтекстовую работу, чтобы снять лексические трудности при чтении текста. Могут быть предложены следующие практические задания:

1. Прочитайте определения симптомов и подберите к ним фразеологические единицы из перечисленных ниже.

2. Прочитайте минитекст и попробуйте определить значение выражения по контексту: Лицо миопата (лицо сфинкса) - термин, обозначающий симптомокомплекс атрофии или пареза мыши лица, характеризующий миопатию. Типичными являются следуюшие признаки расстройства: маскообразное, малоподвижное лиио с вялой, 
маловыразительной мимикой; отсутствие складок на лбу - "полированный лоб"; неспособность наморщить лоб; неспособность полностью закрыть глаза; утолщение и отвисание нижней губы - губы тапира (тапир - животное с вытянутыми в хобот верхней губой и носом).

Возможна также предварительная работа дома - учащиеся сами стараются найти значение заранее обозначенных фразеологических единиц.

Особую сложность представляет освоение фразеологизмов, в основе которых лежит сравнение с мифологическими или литературными персонажами, поскольку они опираются на общую эрудицию и обширные знания культуры и искусства всего мира. Изучение этих фразеологизмов будет направлено не только на усвоение профессиональной лексики, но и на расширение культурологических знаний. Данную работу можно провести на старших курсах в виде отдельного тематического занятия или квеста, к которому учащиеся должны заранее подготовиться. Это потребует от преподавателя больших усилий и подготовки, анализа национальных культурных особенностей и первоначального уровня подготовки группы, ее эрудиции.

\section{4. Выводы}

Медицинская фразеология, не являясь основным предметом изучения на занятиях по русскому языку как иностранному, представляет собой эффективное средство формирования профессиональной коммуникативной компетенции у студентов-иностранцев, помогает усваивать лексические единицы, позволяет преподавателю разнообразить сценарий занятий, использовать интерактивные формы и методы обучения. При этом обучение целесообразно проводить с опорой на классификации, в основе которых лежат структурный или семантический принципы, поскольку традиционное для лингвистики деление фразеологизмов по степени спаянности слов в их составе не может быть использовано в иноязычной аудитории, так как у студентов возникают трудности в понимании этого критерия.

Изучение медицинской фразеологии продуктивно уже на начальном этапе овладения языком профессии. Предложенная в статье система заданий для начального и продвинутого этапов освоения русского языка студентами-медиками обусловлена как структурой, так и семантикой фразеологических единиц и может быть применена не только в медицинском, но и в других вузах, осуществляющих подготовку студентов по другим направлениям.

\section{СПИСОК ЛИТЕРАТУРЫ}

Аркадьева, Э. В. Живая методика преподавания русского языка как иностранного / Э. В. Аркадьева. - М. : Дрофа, 2005. - 345 с.

Гончаренко, Н. В. РКИ для студентов-медиков: активные и интерактивные формы обучения / Н. В. Гончаренко // Русский язык за рубежом. 2014. -№ 5 (246). - C. 4-28.

Ефремова, Н. В. Развитие языковой личности при обучении русскому языку как иностранному / Н. В. Ефремова // Проблемы качества обучения зарубежных граждан в медицинских вузах : IV Bcepoc. науч.-практ. конф. с междунар. участием (23 окт. 2012 г., г. Волгоград). - Волгоград : Волгогр. гос. мед. ун-т, 2012. - С. 216.

Зубкова, О. С. Медицинская метафора как результат культурной фиксации в медицинской терминологии / О. С. Зубкова // Вестник Ленинградского государственного университета имени А.С. Пушкина. Серия «Филология》. -2008 . - № 5 (19). - С. 127-135.

Зубкова, О. С. Метафора в профессиональной семиотике / О. С. Зубкова. - Курск : Изд-во КГУ, 2011. -334 c.

Момот, Е. А. Устойчивые словосочетания. Медицинские фразеологизмы / Е. А. Момот, А. А. Мартиросян, А. К. Газарянц // VIII Международная студенческая конференция «Студенческий научный форум 2016». - 2016. - Электрон. текстовые дан. Режим доступа: http://www.scienceforum.ru/2016 /2149/25475. - Загл. с экрана.

Сотников, Ю. А. Фразеологизмы в медицине / Ю. А. Сотников. - Орск : [б. и.], 2013. - 82 с.

Телия, В. Н. Фразеологизм / В. Н. Телия // Лингвистический энциклопедический словарь / гл. ред. В. Н. Ярцева. - М. : Советская энциклопедия, 1990. C. $559-560$.

\section{СЛОВАРИ}

Криничанский, А. В. Толковый словарь медицинских терминов / А. В. Криничанский, Л. А. Богданова. - Сочи : Сонет, $1992 .-60$ c. 
Покровский, И. В. Энциклопедический словарь медицинских терминов / И. В Покровский. М. : Медицина, 2005. - 1592 с.

Словарь медицинских терминов / сост. А. Е. Колосов, Е. В. Новичков. - Киров : Изд-во КГМА, 2002.- $198 \mathrm{c}$.

\section{REFERENCES}

Arkadyeva E.V. Zhivaya metodika prepodavaniya russkogo yazyka kak inostrannogo [Live Methods of Teaching the Russian Language to Foreigners]. Moscow, Drofa Publ., 2005. 345 p.

Goncharenko N.V. RKI dlya studentov-medikov: aktivnye i interaktivnye formy obucheniya [Russian as a Foreign Language for Medical Students: Active and Interactive Learning]. Russkiy yazyk za rubezhom, 2014, no. 5 (246), pp. 4-28.

Efremova N.V. Razvitie yazykovoy lichnosti pri obuchenii russkomu yazyku kak inostrannomu [The Development of a Language Personality in Teaching Russian as a Foreign Language]. Problemy kachestva obucheniya zarubezhnykh grazhdan $v$ meditsinskikh vuzakh : IV Vseros. nauch.-prakt. konf. s mezhdunar. uchastiem (23 okt. 2012 g., g. Volgograd) [Problems of Quality of Teaching Foreign Citizens in Medical Universities: $4^{\text {th }}$ Russian Scientific and Practical Conference with International Participation (October 2-3, 2012, Volgograd)]. Volgograd, Volgogr. gos. med. un-t Publ., 2012, p. 216.
Zubkova O.S. Meditsinskaya metafora kak rezultat kulturnoy fiksatsii $\mathrm{v}$ meditsinskoy terminologii [The Medical Metaphor as the Result of Cultural Fixation in Medical Terminology]. Vestnik Leningradskogo gosudarstvennogo universiteta imeni A.S. Pushkina. Seriya «Filologiya», 2008, no. 5 (19), pp. 127-135.

Zubkova O.S. Metafora v professionalnoy semiotike [Metaphor in Professional Semiotics]. Kursk, Izd-vo KGU, 2011.334 p.

Momot E.A., Martirosyan A.A., Gazaryants A.K. Ustoychivye slovosochetaniya. Meditsinskie frazeologizmy [Set Phrases. Medical Idioms]. URL: http://www.scienceforum.ru/2016/2149/25475. (accessed March 15, 2017).

Sotnikov Yu.A. Frazeologizmy v meditsine [Idioms in Medicine]. Orsk, 2013.82 p.

Teliya B.N. Frazeologizm [An Idiom]. Yartseva V.N., ed. Lingvisticheskiy entsiklope-dicheskiy slovar [Linguistic Encyclopedic Dictionary]. Moscow, Sovetskaya entsiklopediya Publ., 1990, pp. 559-560.

\section{DICTIONARIES}

Krinichanskiy A.V., Bogdanova L.A. Tolkovyy slovar meditsinskikh terminov [Explanatory Dictionary of Medical Idioms]. Sochi, Sonet Publ., 1992. 60 p.

Pokrovskiy I.V. Entsiklopedicheskiy slovar meditsinskikh terminov [Encyclopedic Dictionary of Medical Terms]. Moscow, Meditsina Publ., 2005. 1592 p.

Kolosov A.E., Novuchkov E.V. Slovar meditsinskikh terminov [Dictionary of Medical Terms]. Kirov, Izd-vo KGMA, 2002. 198 p.

\section{Information About the Authors}

Olga P. Ignatenko, Candidate of Sciences (Philology), Associate Professor, Department of Russian Language and Social Adaptation, Volgograd State Medical University, Pavshikh Bortsov Sq., 1, 400131 Volgograd, Russian Federation, ignatenk-o@mail.ru, http://orcid.org/0000-0003-3149-3015.

Yuliya G. Fateeva, Candidate of Sciences (Philology), Lecturer, Department of Russian Language and Social Adaptation, Volgograd State Medical University, Pavshikh Bortsov Sq., 1, 400131 Volgograd, Russian Federation, fatjg@mail.ru, http://orcid.org/0000-0002-5588-6959.

\section{Информация об авторах}

Ольга Петровна Игнатенко, кандидат филологических наук, доцент кафедры русского языка и социально-культурной адаптации, Волгоградский государственный медицинский университет, пл. Павших Борцов, 1, 400131 г. Волгоград, Российская Федерация, ignatenk-o@mail.ru, http://orcid.org/0000-0003-3149-3015.

Юлия Геннадиевна Фатеева, кандидат филологических наук, старший преподаватель кафедры русского языка и социально-культурной адаптации, Волгоградский государственный медицинский университет, пл. Павших Борцов, 1, 400131 г. Волгоград, Российская Федерация, fatjg@mail.ru, http://orcid.org/0000-0002-5588-6959. 